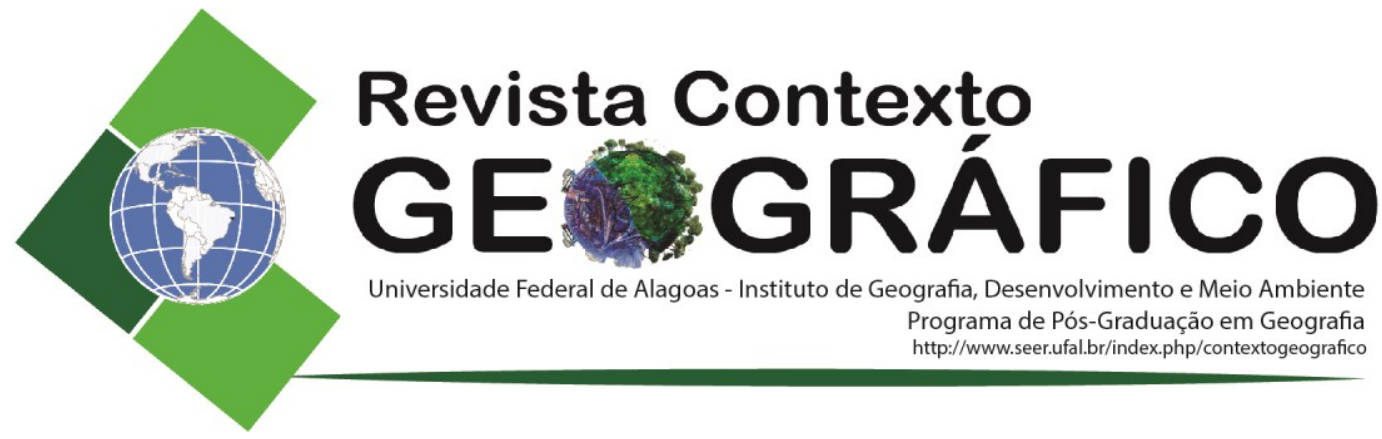

\title{
A RELEVÂNCIA DO ESTÁGIO SUPERVISIONADO EM GEOGRAFIA NA FORMAÇÃO INICIAL DOCENTE
}

\author{
Maria Francineila Pinheiro dos Santos \\ Universidade Federal de Alagoas, Instituto de Geografia, Desenvolvimento e Meio Ambiente, \\ Maceió, AL, Brasil \\ francineila.pinheiro@igdema.ufal.br
}

\begin{abstract}
RESUMO - Este artigo discute a relevância do Estágio Supervisionado em Geografia na formação inicial docente. Nesta perspectiva, o pesquisador utilizou o método "Estado da Arte", no intuito de investigar os conceitos presentes na produção cientifica sobre o Estágio Supervisionado em Geografia nos dois eventos a seguir: Encontro Nacional de Prática de Ensino em Geografia - ENPEG (2009 e 2011), e no Encontro Nacional da Associação de PósGraduação em Geografia - ENANPEGE (2009 e 2011); assim como os aportes teóricos que subsidiam os mesmos. Desse modo, a análise realizada centra-se, a princípio, em investigar e evidenciar a produção acadêmica acerca do estágio, onde destaca os conceitos e as abordagens teóricas na qual estão ancorados os mesmos; e em segundo plano, discute o que constitui e representa o Estágio Supervisionado para os cursos de formação inicial docente. A análise dos dados coletados possibilitou concluir que o Estágio Supervisionado em Geografia é fonte primária de valores identitários imprescindíveis na constituição do sujeito docente, o qual deve estar em constante interação com o ambiente escolar, e com a aprendizagem para a socialização do conhecimento voltado para a construção da cidadania e edificação da identidade docente.
\end{abstract}

Palavras-chave: Estágio Supervisionado; Geografia; Formação Inicial Docente.

\section{LA RELEVANCIA DEL PRACTICUM EN GEOGRAFÍA EN LA FORMACIÓN INICIAL DOCENTE}

\begin{abstract}
RESUMEN - Este artículo discute la relevancia del practicum en la formación inicial docente. En esta perspectiva, se utilizó el método "Estado del Arte" con el fin de investigar los conceptos presentes en la producción científica sobre el practicum en Geografía en los dos eventos siguientes: Encuentro Nacional de Práctica de Enseñanza en Geografía - ENPEG (2009 y 2011) y en el Encuentro Nacional de la Asociación de Postgrado en Geografía - ENANPEGE (2009 y 2011), así como los aportes teóricos que subsidian los mismos. De este modo, el análisis realizado está centrado, en principio, en investigar y evidenciar la producción académica acerca del estadio, destacando los conceptos y los enfoques teóricos en los que están anclados los mismos y en segundo lugar, discutir lo que constituye y representa el practicum para los cursos de formación inicial docente. Los análisis de los datos recolectados posibilitan concluir que el practicum en Geografía es fuente primaria de valores de identidad, imprescindibles en la constitución del sujeto docente, el cual debe estar en constante interacción con el ambiente escolar y con la aprendizaje para la socialización del conocimiento, para la construcción de la ciudadanía y edificación de la identidad docente.
\end{abstract}

Palabras-clave: Practicum; Geografía; Formación Inicial Docente.

\section{INTRODUÇÃO}

Neste artigo, tomamos por objetivo discutir a relevância do Estágio Supervisionado em Geografia na formação inicial docente. Para tanto, pretendemos, inicialmente, investigar a produção cientifica sobre o Estágio Supervisionado nos dois eventos a seguir: Encontro Nacional de Prática de Ensino em Geografia - ENPEG (2009 e 2011), e no Encontro Nacional da Associação de Pós-Graduação em Geografia - ENANPEGE (2009 e 2011), desse modo,

$\begin{array}{llllll}\text { Revista Contexto Geográfico } & \text { Maceló-AL } & \text { V. 2. N.3 } & \text { Julho/2017 } & \text { P. 66-75 } & \text { PÁgina } 66\end{array}$


evidenciaremos os conceitos e os aportes teórico que subsidia os mesmos. E por fim, analisarmo-los vislumbrando a importância desses para a formação inicial docente.

O estágio supervisionado possibilita um aprendizado imperativo para que os licenciandos possam refletir acerca da docência, teorizando sobre o seu objeto de estudo e de ensino, na perspectiva da realidade que vivenciará na condição de docente. Dessa maneira, é possível caracterizar o estágio como sendo todas as "atividades de aprendizagem social, profissional e cultural, proporcionadas ao estudante pela participação em situações reais de vida e trabalho" (Art. $2^{\circ}$ do decreto de $n^{\circ} 87.497$, de 18.08.82) $)^{1}$. Compreender o que representa o estágio supervisionado para a formação inicial é uma questão fundamental para vivenciá-lo na prática do cotidiano educacional, ou seja, para a profissão docente.

A partir do diálogo com alguns autores, que se debruçam sobre o Estágio Supervisionado, a saber: Barreiro e Gerbran (2006), Pimenta e Lima (2010) e Santos (2012), foi possível fazer alguns questionamentos sobre a produção acadêmica acerca do estágio supervisionado em Geografia: o que se tem produzido sobre esta temática no período de 2009 a 2011? Após a Resolução CNE/CP $n^{\circ} 1$, de 18 de fevereiro de 2002, que regulamenta o mesmo, ocorreu um maior interesse dos pesquisadores por esta temática? Que conceitos e aportes teórico têm destaque nos trabalhos sobre Estágio Supervisionado em Geografia?

Verificar o que vem sendo produzido acerca do Estágio Supervisionado em Geografia é de extrema relevância, tendo em vista que a Resolução CNE/CP ${ }^{\circ}$ 1, de 18 de fevereiro de 2002, a qual regulamenta o Estágio Supervisionado, completa quinze anos de sua implantação. Com esta perspectiva, iremos, neste artigo, demonstrar os aportes teóricos presentes na produção cientifica sobre o Estágio Supervisionado em Geografia nos dois referidos eventos.

\section{METODOLOGIA}

Para o desenvolvimento do trabalho, optamos pelo método Estado da Arte, o qual segundo Fiorentini e Lorenzato (2007, p.70) “[...] se propõe a realizar análises históricas e/ou revisão de estudos ou processos tendo como material de análise documentos escritos e/ou produções culturais". Entendemos que, inventariar produções acadêmicas de diversas áreas do conhecimento em busca de respostas às diferentes problemáticas tem mobilizado pesquisadores a desenvolverem estudos bibliográficos da produção acadêmica.

Nessa metodologia, o pesquisador analisa os instrumentos de coleta de dados, conseguindo extrair categorias de análises que reflitam os propósitos da pesquisa, revelando-se uma técnica bastante útil (FIORENTINI e LORENZATO, 2007). Para tanto, houve consulta aos anais do ENPEG (2009 e 2012) e ENANPEGE (2012) para verificarmos se o Estágio Supervisionado tem se apresentado como objeto de estudo, para isso, realizamos o download dos resumos para leitura e identificação dos quadros teóricos, dos métodos utilizados e as conclusões, buscamos também, analisar as possíveis similitudes entre as pesquisas e quais assuntos e temas são recorrentes.

Posto isso, analisamos a produção acadêmica relacionada ao Estágio Supervisionado em Geografia, buscando expor os conceitos e os aportes teórico que baseiam a temática nos dois eventos: ENPEG (2009 e 2012) e ENANPEGE (2009 e 2011). E, por fim, elaboramos os gráficos resultantes da análise dos dados, assim como o texto que será discutido aqui a partir da análise.

${ }^{1}$ BRASIL. Decreto Lei No. 87.497, de 18 de agosto de 1982. Brasília/DF/BR. Disponível em: $<$ http://www.planalto.gov.br/ccivil 03/decreto/d87497.htm> Acesso em: 22/11/2010. 


\section{RESULTADOS E DISCUSSÃO}

\section{O Estágio Supervisionado em Geografia}

O estágio supervisionado em Geografia deve estar consubstanciado na articulação teoria-prática, no fortalecimento da identidade docente e na formação do professor-pesquisador. Com essa perspectiva, esperamos que o licenciando possa teorizar sobre o seu objeto de estudo e de ensino na condição de profissional, ampliando a compreensão das situações vivenciadas na escola, refletindo sobre a profissão docente, onde o pensar e o fazer pedagógico só encontram razão a partir de uma existência crítica, dinâmica e construtiva.

Pimenta e Lima (2010, p. 29) apontam que ao pensar o Estágio Supervisionado enquanto local propício para a pesquisa acabou por atribuí-lo a "um estatuto epistemológico que visa superar a sua tradicional redução à atividade prática instrumental". A perspectiva de desenvolver pesquisas no estágio traz benefícios tanto para os professores orientadores - os quais podem aplicá-las no ambiente escolar - quanto para a escola e os estagiários, os quais serão introduzidos na investigação, instigando-os a refletirem acerca do seu papel enquanto docentes de Geografia.

Desse modo, o estágio pode viabilizar a práxis docente consubstanciada numa formação articulada com diferentes posturas educacionais, porém com uma mesma finalidade: a formação docente qualitativa que objetiva aos diversos saberes contemporâneos, possibilitando aos futuros docentes desenvolverem a reflexão e análise acerca do contexto escolar e sobre as responsabilidades do docente frente à transformação do mundo, enriquecendo sua formação acadêmica através de uma ação reflexiva.

No que diz respeito à análise dos trabalhos presente nos Anais do ENPEG (2009 e 2012) e ENANPEGE (2009 e 2011), destaca-se os seguintes temas (Figura 1).

Figura 1. Trabalhos que tratam de Estagio Supervisionado e temas relacionados ao mesmo.

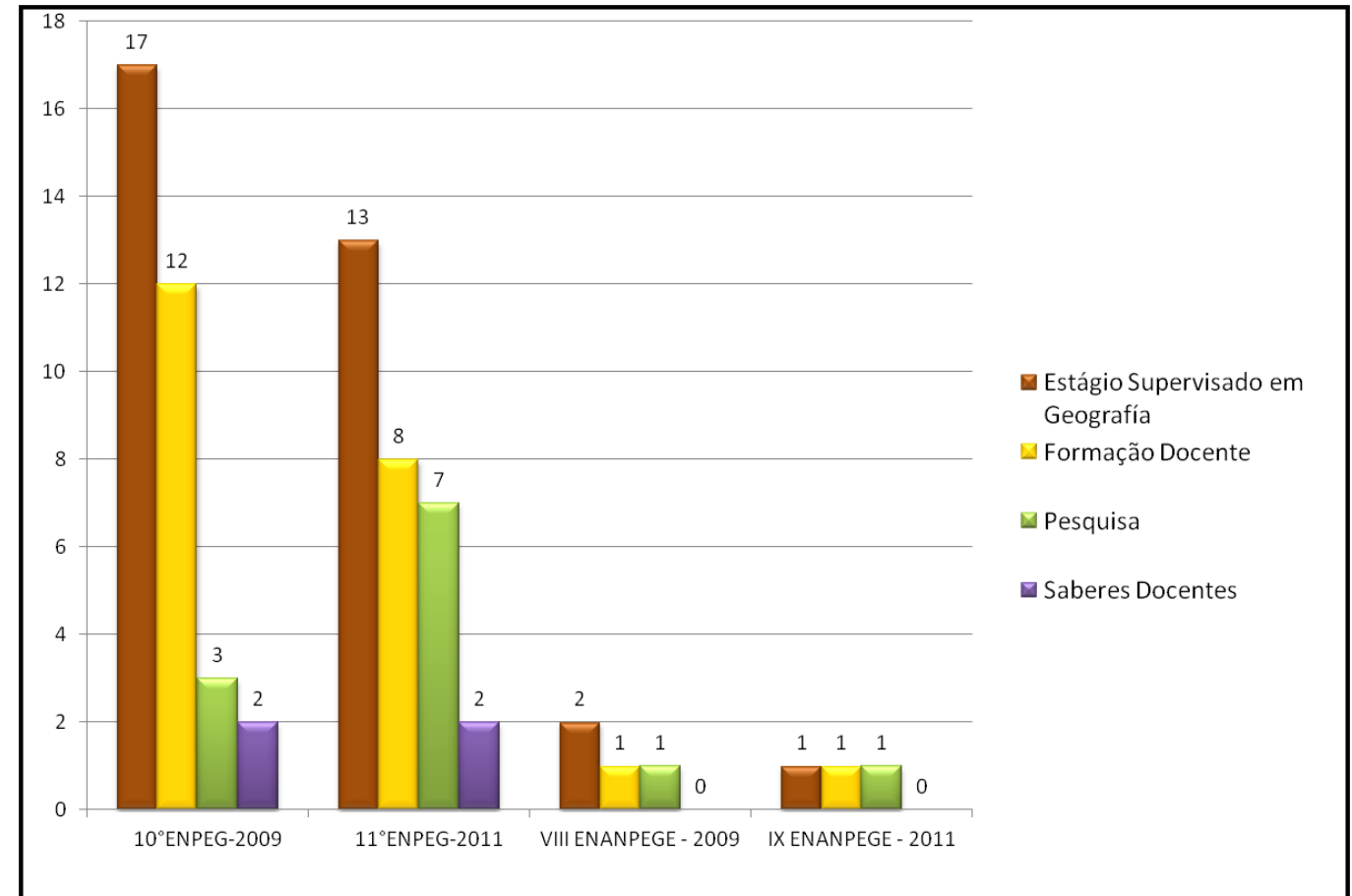

Fonte: SANTOS, (2017). 
De acordo com a figura 1, observa-se que a maioria dos trabalhos, no total de 33 aborda o Estágio Supervisionado. Na sequência, temos a Formação Docente com 22 trabalhos, a Pesquisa com 12 e, por fim, Saberes Docentes com apenas 4 trabalhos. Nesta perspectiva, o estágio é entendido como uma "atividade teórica de conhecimento, fundamentação, diálogo e intervenção, esta, sim, objeto da práxis" (PIMENTA e LIMA, 2010, p. 45).

Em relação ao aporte teórico que subsidia o conceito de estágio, e os demais temas vislumbrados anteriormente, os mesmos estão baseados nas ideias de distintos autores, como podemos observar na figura 2 .

Tabela 2: aportes teóricos presentes nos trabalhos sobre estágio e os demais temas em foco

\begin{tabular}{|c|c|c|}
\hline Conceitos & Quantidade & Autores \\
\hline \multirow[t]{3}{*}{ Estagio Supervisionado } & 12 & Pimenta e Lima $(2004,2005,2010)$ \\
\hline & 3 & Ghedin (2006) \\
\hline & 2 & Barreiro e Gebran (2006) \\
\hline \multirow[t]{4}{*}{ Formação Docente } & 5 & Cavalcanti $(2002,2006)$ \\
\hline & 4 & Pimenta e Lima $(2004,2009)$ \\
\hline & 3 & Callai (2006) \\
\hline & 2 & Nóvoa $(1995,1996)$ \\
\hline \multirow[t]{3}{*}{ Pesquisa } & 5 & Pimenta e Lima $(2004,2005,2010)$ \\
\hline & 3 & Zeichner $(1995,1998,2002)$ \\
\hline & 2 & Pontuschka, Pganelli, Cacete (2007) \\
\hline \multirow[t]{2}{*}{ Saberes Docentes } & 3 & Tardif $(2002,2004)$ \\
\hline & 2 & Cavalcanti $(1998,2005)$ \\
\hline
\end{tabular}

Fonte: SANTOS, (2017).

Para uma melhor análise dos aportes teóricos que fundamentam os mesmos, iremos abordá-los separadamente.

\section{FORMAÇÃO DOCENTE}

A Formação Docente discute concepções e práticas que levem à reflexão sobre docência no intuito de promover os saberes geográficos articulados com a teoria, possibilitando ao professor uma análise integrada e sistemática da sua didática baseada na intervenção e na investigação. Por isso, é imprescindível que os cursos de Licenciatura em Geografia desenvolvam nos futuros docentes conhecimentos e habilidades, estabelecendo um vínculo com o contexto institucional e social em que se inserem, promovendo pesquisas ao longo da formação inicial que possibilite tal processo, além de contribuir para a reflexão da prática docente.

Castellar (2010, p. 40) acrescenta que os cursos de formação inicial não devem se consubstanciar somente nos aspectos conceitual e teórico, mas também têm que se preocupar em "[...] incorporar referenciais no campo das dimensões econômicas, sociais e culturais, com uma visão de mundo que incorpore o lugar onde vivem os alunos e docentes, as singularidades e os conflitos de valores". Desse modo, todos nós, docentes, devemos estar atentos à realidade dos nossos alunos e aos valores culturais e sociais no qual estes se encontram imersos, na tentativa de que, a partir do seu cotidiano, possam realizar suas leituras de mundo. 
As perspectivas na Formação do Docente em Geografia devem estar pautadas no intuito de "[...] articular teoria e prática, ter na pesquisa a ferramenta principal de seu ofício, exercitar a reflexão de forma permanente e promover a aprendizagem de todos os alunos" (SANTOS, 2010, p. 63). Não é possível fragmentar a prática em relação à teoria docente e separá-las sem que haja prejuízo no entendimento deste processo. Ambas precisam ser consideradas no processo de formação docente.

Em decorrência das questões expostas, destacamos a sugestão de Cavalcanti (2006, p. 46-47) de que a formação inicial deve "articular teoria e prática; integrar ensino e pesquisa; atentar para as diferentes capacidades e habilidades requeridas para o trabalho profissional e promover a continuidade da profissionalização". Somente desta maneira alcançaremos uma Educação Geográfica, na qual os professores exerçam à docência de forma crítica e criativa, buscando sempre a consonância do ensino e da pesquisa na sua práxis docente.

Segundo Gómez (1995), o professor deveria desde a sua formação inicial adotar a reflexão em sua prática, seja nos estágios ou em sua sala de aula. Dessa forma, ele se tornaria um investigador, não dependendo de técnicas derivadas de uma teoria externa, nem mesmo de prescrições curriculares impostas do exterior pela administração escolar. Essa concepção vê a formação do professor como um profissional reflexivo, e aponta que ele deve atuar refletindo na ação, experimentando, corrigindo e inventando, desse modo, indo além das teorias e procedimentos conhecidos, ou seja, trilhando novos caminhos.

As colocações apresentadas apontam para a necessidade de a formação inicial docente enfatizar "[...] os conteúdos de forma que incorporem os princípios didáticos pedagógicos dos mesmos. Ao vivenciar as formas de aprender e compreender Geografia o graduando poderá estabelecer as bases para ensinar a Geografia" (CALLAI, 2010, p.418-419) sendo esta uma questão crucial na formação dos docentes de Geografia, necessária para qualificar sua atuação docente.

Entendemos que tudo isso perpassa por uma visão tradicional ainda vigente, de que a teoria serve apenas para auxiliar no entendimento da realidade e a prática é a sua aplicação. Esta visão compreende uma concepção alheia aos ditames da formação inicial na atualidade. Pois a integração de ambas deve permear à docência em Geografia, priorizando a contextualização do que se aprende na academia e do que é instruído no cotidiano profissional.

Essa é uma das nossas preocupações e, por isso, acreditamos que a pesquisa na formação inicial docente, enquanto instrumento de articulação entre as teorias desenvolvidas na universidade e as práticas discutidas no ambiente escolar, possibilita que os futuros professores de Geografia percebam a importância dessas na profissão e futuramente na sua práxis docente.

A Prática docente, segundo Pimenta (2005, p. 17-18) deve buscar desenvolver nos alunos "[...] conhecimentos e habilidades, atitudes e valores que lhes possibilitem permanentemente irem construindo seus saberes-fazeres docentes a partir das necessidades e desafios que o ensino com prática social lhes coloca no cotidiano". Desse modo, devemos estar atentos sobre o que se espera do trabalho docente, especialmente no que se refere ao desenvolvimento dos conhecimentos e habilidades que os auxiliem na construção dos saberes e fazeres docentes. $\mathrm{O}$ docente deve estar atento à crise atual da escola para, a partir disso, pensar em ações que garantam o processo de ensino-aprendizagem.

Mas, é interessante discutirmos acerca dos ambientes escolares, pois esses não são espaços naturais, e sim sociais, onde se encontram grupos de atores que influenciam de diversas maneiras na escola, impondo-lhe seus próprios fins, como bem ressalta Tardif (2008 p. 196) ao afirmar que os objetivos da escola influenciam nos fins do trabalho docente, pois esse compreende "[...] uma tarefa dinâmica com efeitos imprecisos e longínquos que requerem a 
iniciativa dos professores; eles precisam interpretá-los e adaptá-los constantemente aos contextos movediços da ação pedagógica". Dessa maneira, existe uma necessidade de um movimento de reflexão acerca do que objetiva à docência, a escola e o trabalho docente, possibilitando um entendimento do que cada um proporciona no exercício da docência.

Nesse contexto, Callai $(2005$, p. 228-229) aponta que o ensino de Geografia deve "[...] ler o mundo da vida, ler o espaço e compreender que as paisagens que podemos ver são resultado da vida em sociedade, dos homens na busca da sua sobrevivência e da satisfação das suas necessidades". O intuito é fazer com que o aluno se perceba em seu cotidiano, na paisagem da sua rua e nas desigualdades que se apresentam nos lugares em que vive, e a partir disso se posicione com autonomia, criatividade e criticidade diante da realidade. Por isso a necessidade que ocorra a construção dos conhecimentos geográficos, de modo que os alunos se percebam no seu cotidiano, entendendo que os mesmos fazem parte do espaço geográfico, interferindo positiva ou negativamente, dependendo de suas ações enquanto produtores do espaço.

Nessa perspectiva, a Prática Docente deve ser consubstanciada na construção de saberes, a qual, segundo Castellar (2010, p. 56) deve objetivar "[...] não só dominar conteúdos, mas ter, ao mesmo tempo, um discurso conceitual organizado com uma proposta adequada de atividade, buscando superar os obstáculos da aprendizagem". Essa concepção permite que o professor de Geografia tenha o domínio do conhecimento específico de sua área e do conhecimento pedagógico no intuito de atuar de modo decisivo como agente de transformação no seu ambiente de trabalho - a escola.

Quando prática e teoria estão articuladas ao ensino ocorre uma concretização de competências e habilidades necessárias à docência, de forma contextualizada e relacionada ao momento atual em que se ensina ou se aprende. Esta articulação saber-fazer é fundamental na ação docente, inclusive, constituindo-se em um entrave no trabalho docente daqueles que não conseguem estabelecer esta relação.

Os docentes de Geografia precisam se debruçar de forma mais incisiva sobre as concepções teórico-metodológicas que balizam o seu ensino, pois conforme salienta Castellar (2010, p. 3940), isto ajudaria estimular "[...] a sua autonomia, o que por sua vez possibilita mudanças didático-pedagógicas que incidem, diretamente, na formação cognitiva, ética e estética dos docentes em um contexto sociocultural". Desse modo, cabe aos professores de Geografia construir conjuntamente com os alunos as informações que os mesmos já possuem em conhecimentos, relacionando-os com o cotidiano dos alunos, dando assim significado e importância aos conteúdos geográficos no ambiente escolar.

\section{PESQUISA}

A pesquisa na formação inicial pode viabilizar a práxis docente consubstanciada numa preparação articulada com diferentes posturas educacionais, porém com uma mesma finalidade: a formação docente qualitativa que objetiva aos diversos saberes contemporâneos.

Nessa direção, Ghedin e Franco (2008, p. 15) enfatizam que "o elemento que faz imbricamento entre a teoria e a prática é a pesquisa que se desenvolve ao longo de toda formação profissional". Desse modo, a pesquisa possibilita aos futuros docentes desenvolverem a reflexão e análise acerca do contexto escolar e sobre as responsabilidades do docente frente a transformação do mundo, enriquecendo sua formação acadêmica através de uma ação reflexiva.

Autoras como Pontushcka, Paganelli e Cacete (2007) destacam a relevância da pesquisa na construção do conhecimento geográfico dos docentes de Geografia, na qual a pesquisa é um 
elemento facilitador da articulação teoria e prática. Nesse contexto, a pesquisa possibilitaria a formação de docentes críticos e reflexivos, através de uma atitude investigativa, envolvendo a reflexão acerca do ambiente escolar.

Nessa perspectiva, entendemos que a pesquisa não deve acontecer somente na formação inicial. A mesma deve ocorrer de forma permanente, integrada entre os docentes da escola e os licenciandos, transformando-se em projetos de extensão, incluindo aí a comunidade local. Pois, se não houver uma integração, discussão e planejamento de atividades que beneficiem a ambos na construção do conhecimento, o processo educativo não ocorre.

Neste âmbito, Miranda (2008, p. 17) afirma que a pesquisa “[...] aproxima mais o aluno da escola, desenvolvendo posturas e habilidades de pesquisador que busca compreender os fatores determinantes da realidade escolar e propor projetos de ação". Desse modo, a pesquisa, além de permitir ao licenciando analisar o ambiente escolar, ainda o estimula a pensá-lo de forma crítica, propondo situações de intervenção que visem transformar a realidade da escola.

De acordo com Pontuschka (2010, p. 464) a pesquisa na formação docente poderá propiciar "[...] a integração entre o descobrir, o aprender e o ensinar: o aluno pesquisador pode emergir e ser capaz de levar a pesquisa para os seus futuros alunos do ensino fundamental e médio". A autora demonstra que a prática docente deve ocorrer de forma contextualizada, no entendimento das relações que permeiam a escola. E, principalmente, que deve haver um processo relacional constante entre a escola e o cotidiano que a cerca, promovendo uma relação de troca, benéfica para todos.

A pesquisa na formação inicial possibilita a concretização de um espaço privilegiado, articulador da pesquisa, reflexão e ensino, ambiente propício para a formação do professorpesquisador. Bortoni-Ricardo (2008, p.46) aponta o professor-pesquisador como "[...] aquele que não se vê apenas como um usuário do conhecimento produzido por outros pesquisadores, mas se propõe também a produzir conhecimentos sobre seus problemas profissionais, de forma a melhorar sua prática". Desse modo, a pesquisa é o instrumento essencial para que o professorpesquisador possa construir seus conhecimentos a partir da prática que está vivenciando.

A articulação entre a pesquisa e a reflexão, com uma prática articulada à teoria abrirá caminho para uma formação de qualidade, na qual o futuro docente terá condições propicias para investigar a sua prática. E na medida em que intervém neste espaço, acaba por contribuir com mudanças mais amplas, ou seja, da sociedade em geral na medida em que se tem uma formação docente mais condizente com os ditames da contemporaneidade.

Assim sendo, avanços significativos podem ocorrer na formação desses docentes enquanto professor-pesquisador. Desse modo, o conhecimento se torna significativo, quase palpável e é moldado de acordo com cada realidade, proporcionando uma aplicabilidade que transforma a realidade no ambiente de aprendizagem. A necessidade de uma conscientização crítica e construtiva a respeito do conhecimento se torna uma exigência ao ensinar e um benefício por parte de quem aprende, oportunizando a aplicabilidade da pesquisa realizada.

A pesquisa na formação docente acaba contribuindo com o desenvolvimento profissional dos futuros docentes de Geografia, sendo que a sociedade exige cada vez mais profissionais dinâmicos e criativos. Além disso, essa autonomia ajusta a medida entre a pesquisa e a formação docente, estimulando uma construção do conhecimento pautada pela responsabilidade docente.

Todas essas proposições levam-nos a concordar com o pensamento de Cavalcanti (2006, p. 111) ao afirmar que cada vez mais a "[...] formação tem se tornado responsabilidade do próprio profissional, começando no período de sua formação básica, no curso de nível universitário, 
mas não se reduzindo a isso, tendo continuidade em toda sua trajetória profissional". Daí a importância da pesquisa enquanto possibilidade para estes futuros docentes se perceberem como protagonistas de seu próprio desenvolvimento profissional.

\section{SABERES DOCENTES}

Os saberes da docência constituem-se de três pilares: da experiência, do conhecimento e pedagógicos (PIMENTA, 2005a). Segundo Pimenta (2005a, p.20), os saberes da experiência são "[...] aqueles que os professores produzem no seu cotidiano docente, num processo permanente de reflexão sobre sua prática, mediatizada pela de outrem - seus colegas de trabalho, os textos produzidos por outros educadores". Assim, o professor deve ser um eterno pesquisador, em busca de aprimorar cada vez mais esses três saberes, para que a sua prática em sala de aula, possa proporcionar um processo de aprendizagem significativo para o aluno.

Quanto ao conhecimento, a preocupação concentra-se não apenas na sua produção, mas muito mais em propiciar as condições necessárias para que ocorra a construção do conhecimento por parte dos alunos.

Os saberes pedagógicos são produzidos a partir da sua própria ação docente, na qual "Os profissionais da educação, em contato com os saberes sobre a educação e sobre a pedagogia, podem encontrar instrumentos para se interrogarem e alimentarem suas práticas, confrontandoos" (PIMENTA, 2005a, p.26). Trocar conhecimento com outras áreas do saber é importante para enriquecer a didática em sala de aula, pois cada aluno é um mundo e o professor tem que se permitir trocar, aprender e instigar para que o seu aluno sinta-se o centro do processo de aprendizagem e assim adquira a autonomia necessária para construir o seu próprio saber.

Segundo Pimenta (2005b, p. 24), “o saber docente não é formado apenas da prática, sendo também nutrido pelas teorias da educação. [...], pois a teoria dota os sujeitos de variados pontos de vista para uma ação contextualizada, oferecendo perspectivas de análise". Localizar-se no contexto educacional é um critério imprescindível para a prática docente, reconhecendo o ambiente onde se ensina e conhecendo os sujeitos para quem o ensino é proposto.

A importância das teorias da educação na articulação deste saber-fazer na formação docente é o que Castellar (2010, p. 42) define como "[...] integrar as bases teóricas com a prática cotidiana e, dessa maneira, os docentes teriam uma dimensão maior do significado dos saberes específicos e das práticas sociais". Daí a necessidade dessa articulação tanto para o docente promover um ensino de qualidade, quanto para o aluno perceber e construir uma educação participativa e emancipatória.

No entanto, para uma ação educativa significativa, Pimenta e Lima (2010, p. 68) enfatiza que a mesma requer uma série de "[...] saberes de uma prática reflexiva, saberes de uma teoria especializada, saberes de uma militância pedagógica, o que coloca os elementos para produzir a profissão docente". Esses saberes fazem parte das exigências dispostas ao docente, uma vez que a sociedade contemporânea demanda, cada vez mais, de profissionais criativos, dinâmicos e autônomos, capazes de solucionar problemas no âmbito escolar, os quais requerem saberes vinculado a uma prática pedagógica pautada em sólidos conhecimentos.

Na discussão sobre o saber-fazer docente, Silva (2008, p. 44) enfatiza que "o fazer e o aprender docentes demandam investimentos em situações educativas planejadas e consistentes, caracterizadas por uma postura crítica, criativa, que valoriza os atos de escutar, participar, construir e intervir numa dada realidade educativa". Desse modo, seguindo nossas reflexões, defendemos que a aproximação da escola com a universidade e a comunidade por meio de 
projetos de extensão, configura-se como uma proposta enriquecedora na produção desses saberes no processo de formação docente.

Com esta perspectiva, podemos ultrapassar a ideia da escola apenas como o local de transmissão de conteúdo, mas sim, integrar a escola, a universidade e a comunidade, e ainda ampliar os saberes docentes. A partir disso, os docentes de Geografia terão a oportunidade de estabelecer um diálogo entre o conhecimento geográfico, a cultura local e as necessidades da escola, ampliando os saberes docentes e construindo uma Educação Geográfica.

\section{CONSIDERAÇÕES FINAIS}

A análise dos trabalhos presente nos Anais dos ENPEG (2009 e 2011) e ENANPEGE (2009 e 2011) demonstrou que os temas que mais se destacaram foram o Estágio Supervisionado, e na sequência Formação Docente, Pesquisa e Saberes Docentes. Em relação aos aportes teóricos temos distintos autores (as) que discutem a Educação como um todo, e ainda aqueles que se dedicam mais especificamente ao Ensino de Geografia. Esses dados possibilita um panorama sobre os conceitos e os aportes teóricos que fundamentam as discussões sobre a formação inicial docente em Geografia, assim como a importância do Estágio Supervisionado neste processo.

A análise dos dados coletados permite concluir que o Estágio Supervisionado em Geografia é visto enquanto uma possibilidade para que os licenciandos possam interagir com o conhecimento através de experiências concretas, buscando responder as demandas vivenciadas na formação inicial docente. Ao trilhar caminhos apropriados e em conformidade com as exigências do docente na atualidade, o estágio enquanto espaço de pesquisa contribui para que a universidade gere novos espaços de diálogo e convivência em torno da formação inicial docente de qualidade.

O Estágio Supervisionado foi alvo de alguns avanços, notadamente devido as reformas curriculares pelo qual tem passado o mesmo na última década, dentre elas: o aumento da carga horária e a construção de um projeto pedagógico específico para a Licenciatura. No entanto, para estes avanços realmente apresentarem implicações positivas, faz-se necessário que as instituições formadoras assumam compromisso em construir projetos pedagógicos que atendam às exigências postas à formação docente de qualidade, entendendo o estágio enquanto momento ímpar neste processo, o qual poderá propiciar aos licenciandos desenvolverem as habilidades de professor-pesquisador, construir conhecimentos a partir da articulação teoria-prática e, fortalecer a identidade docente.

Por fim, cabe destacar que as reformas curriculares nos cursos de formação de professores, propiciaram outra condição para o desenvolvimento de estágios supervisionados, no qual os licenciandos devem participar deste processo imbuído em uma perspectiva crítica e comprometida com a escola, consubstanciada de compromissos éticos e sociopolíticos da profissão como aspectos que participam da construção do "ser" docente.

\section{AGRADECIMENTOS}

Este artigo é resultante de parte da pesquisa intitulada: "Estado da Arte: pesquisas sobre estágio supervisionado em Geografia nas universidades federais e estaduais da região Nordeste/Brasil no período de 2002-2012", financiada pelo Programa Institucional de Bolsas de Iniciação Cientifica - PIBIC. Desse modo, meus sinceros agradecimentos a CNPq e FAPEAL que financiaram a referida pesquisa. 


\section{REREFÊNCIAS}

BORTONI-RICARDO, Stella Maris. O professor pesquisador: introdução à pesquisa qualitativa. São Paulo: Parábola Editorial, 2008.

BRASIL. Conselho Nacional de Educação. MEC. Parecer CNE/CP nº 2, de 19 de fevereiro de 2002. Institui a duração da carga horária dos cursos de licenciatura, de graduação plena, de formação de professores da Educação Básica em nível superior.

MEC. Parecer CNE/CP n 2, de 19 de fevereiro de 2002. Institui a duração da carga horária dos cursos de licenciatura, de graduação plena, de formação de professores da Educação Básica em nível superior.

MEC. Decreto no 87.497, de 18 de agosto de 1982. Regulamenta a Lei n. 6.494/77.

CALLAI, Helena Copetti. A educação geográfica na formação docente: convergências e tensões. In: SANTOS, Lucíola L. C. P. (Org.). Convergências e tensões no campo da formação e do trabalho docente. Belo Horizonte: Autêntica, 2010.

Aprendendo a ler o mundo: a geografia nos anos iniciais do ensino fundamental. Caderno Cedes. Maio/Ago. 2005, n. 66. p. 227-247.

CASTELLAR, Sonia M. V. Educação geográfica: formação e didática. In: MORAIS, E. M. B. de; MORAES, L. B. (Orgs.) Formação de professores: conteúdos e metodologias no ensino de Geografia. Goiânia: NEPEG, 2010.

CAVALCANTI, Lana de S. Geografia escolar na formação e prática docentes: o professor e seu conhecimento geográfico. Encontro Nacional de Didática e Prática de Ensino. Recife: ENDIPE, 2006.

FIORENTINI, Dário; LORENZATO, Sérgio (2007). Investigação em educação matemática percursos teóricos e metodológicos. ( $2^{\mathrm{a}}$ edição). Campinas: Autores Associados.

GHEDIN, Evandro; FRANCO, Maria Amélia. Questões de método na construção da pesquisa em educação. São Paulo: Cortez, 2008.

MIRANDA, Maria I. Ensino e pesquisa: o estágio como espaço de articulação. In: SILVA, Lázara C.; MIRANDA, Maria I. (Orgs.). Estágio Supervisionado e prática de ensino: desafios e possibilidades. Araraquara, SP: Junqueira \& Marin: Belo Horizonte, MG: FAPEMIG, 2008.

PIMENTA, Selma G. Formação de professores: identidade e saberes da docência. In: Saberes pedagógicos e atividade docente. $4^{\mathrm{a}} \mathrm{Ed}$, São Paulo: Cortez, 2005a.

Professor reflexivo: construindo uma crítica. In: PIMENTA, Selma G.; Ghedin, Evandro. $\overline{(\mathrm{ORGS})}$ Professor reflexivo no Brasil: gênese e crítica de um conceito. $3^{\mathrm{a}} \mathrm{Ed}$. São Paulo: Cortez, $2005 \mathrm{~b}$.

PIMENTA, Selma G. LIMA, Maria. S. L. Estágio e Docência. 5a Ed, São Paulo: Cortez, 2010.

PONTUSCHKA, Nídia N. A formação inicial do professor: debates. In: SANTOS, Lucíola L. C. P. (Org.). Convergências e tensões no campo da formação e do trabalho docente. Belo Horizonte: Autêntica, 2010.

PONTUSCHKA, N. N; PAGANELli, T.I; CACETE, N. H. Para ensinar e aprender Geografia. São Paulo: Cortez, 2007.

SANTOS, Clézio. Os cursos de formação de professores de Geografia: reflexões e análises centradas em instituições públicas. Caminhos de Geografia. Fev. 2006, v. 7, n. 17. p. 62-71. Disponível em: $<$ http://www.ig.ufu.brqrevistaqcaminhos.html $>$. Acesso em: 22 out. 2010.

TARDIF, M. O trabalho docente: elementos para uma teoria da docência como profissão de interações humanas/ Maurice Tardif, Claude Lessard: tradução de João Batista Kreuch. 4 ed. Petrópolis, RJ: Vozes, 2008. 